\title{
O SUJEITO BILÍNGUE NOS ENSAIOS DE MONTAIGNE
}

Gilson Ramos Lopes Neto Júlia Costa Mendes Isabella Mozzillo

\section{RESUMO}

O Senhor de Montaigne posiciona-se positivamente à prática do bilinguismo em seus Ensaios pós-Renascentistas. Com base na literatura contemporânea das Línguas em Contato, propóe-se, no presente trabalho, diálogo entre um excerto da referida obra e mitos e crenças ligados ao indivíduo bilíngue. Sugere-se, assim, que o plurilinguismo predomina em vez do monolinguismo desde os tempos quinhentistas.

PALAVRAS-CHAVE: Bilinguismo; Montaigne; Os Ensaios.

\section{Introdução: a obra e o autor}

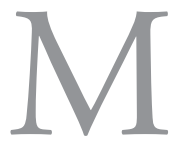
ichel Eyquem de Montaigne (1533 - 1592) foi um magistrado, homem público e filósofo questionador de conceitos e pré-conceitos imperantes no Renascimento artístico-cultural do Continente Europeu. Nascido na localidade do Périgueux, atual região da Aquitânia - sul da França -, o Senhor de Montaigne veio ao mundo durante o apogeu da Renascença Francesa. Essa época se caracterizou por um importante período de consolidação da Monarquia dos Valois, pouco posterior à Guerra dos Cem Anos travada entre França e Inglaterra. O contraste entre a Era das Trevas da Idade Média e a Era das Luzes do Renascimento Italiano teriam oportunizado ao filósofo condiçốes ideais para a sua contribuição à Literatura e à Filosofia ocidental, sendo relido e reanalisado até a contemporaneidade. 
A partir de seus 38 anos de idade, o filósofo entrou num longo período de ócio letrado, momento no qual nasceram Os Ensaios. Escrita em primeira pessoa e desprezando a alta normatização literária pós-Renascença, essa legítima quebra de estética com a sua época deu origem a um gênero textual ainda não experimentado: o ensaio. Esses essais - textos, tentativas ou, literalmente, ensaios em português - visaram desempenhar estratégia empírica e pragmática de raciocínio, pondo a tradição sociocultural em xeque. O Senhor de Montaigne propôs relevantes reflexôes, assistemáticas e não lineares, que focavam na única e mera descrição da sua sincronia num contexto pós-medieval, tendo buscado situar o Homo sapiens sapiens na natureza. A sua masterpiece teria sido elaborada em 1570 e sistematicamente retocada e modificada até 1592, ano de falecimento de Montaigne. Os Ensaios legitimam a atemporalidade de sua essência, ou seja, eles tendem a ser considerados atuais em qualquer etapa evolutiva da humanidade no âmbito sociocultural desde o Renascimento do Ocidente.

A obra poderia ser concebida como uma coletânea de cartas nas quais ele teria escrito sobre si mesmo por meio de longos diálogos com um eventual leitor, servindo-se predominantemente de vocabulário acessível, apesar de culto, e sem artifícios, porém com erudição greco-romana. Montaigne, assim, marca a sua época por dar início ao paradigma da livre análise de livros e de doutrinas, por criticar a tradição na qual está imerso e por propor um exercício metódico para alcançar uma reflexão sobre o homem e o mundo. Defende o princípio da harmonia cujo todo é indivisível, sendo o homem, ao mesmo tempo, carne e espírito, corpo e alma ${ }^{1}$.

O Senhor de Montaigne, num momento específico dos Essais, explicita o papel e a importância das línguas naturais universais e de contato. Estas, para fins de melhor desempenhar suas atividades rotineiras, e aquelas, para fins de erudição. Esse posicionamento do filósofo em sua obra quincentenária motivou a elaboração do presente artigo que dará ênfase a dois parágrafos dessa masterpiece montaigneana que se fazem fundamentais para o recorte aqui proposto. Assim, será analisada a importância do bilinguismo na época de Montaigne - legitimando-o ou desconstruindo-o -, se (e de que maneira) o bilinguismo influenciava a vida do autor, propondo, inclusive, um diálogo com

1 Parágrafos fundamentados na entrevista de Sérgio Xavier Gomes de Araújo à Univesp TV em 2013 (ARAÚJO, 2013). 
alguns mitos e crenças no que tange ao sujeito bilíngue discutidos na literatura contemporânea das Línguas em Contato.

\section{Fragmento analisado}

O objeto de observação proposto neste artigo é oriundo de uma coletânea de textos selecionados da obra, cujo título é Les Essais: Textes choisis (MONTAIGNE, 1976, p. 173 e 175). O excerto, ilustrado à coluna da esquerda na Tabela 1 logo a seguir, está presente no capítulo 35 intitulado "Une douceur sévère..." (em português, Uma doçura severa...) acerca do tema "L’institution scolaire" (A instituição escolar). Na versão impressa da obra completa, datada de 1870 (MONTAIGNE, 1870, p.124-126), o capítulo acima referido origina-se de um fragmento do capítulo XXVI denominado "De l'institution des enfans" (no francês contemporâneo, "De l'institution des enfants" e, em português, $D a$ Educação das Crianças). À coluna da direita da Tabela 1, encontra-se a tradução do excerto para o português por Sérgio Milliet (MONTAIGNE, 1961).

Je voudrais premièrement bien savoir ma langue, et celle de mes voisins où j'ai plus ordinaire commerce. C'est un bel et grand agencement sans doute que le Grec et Latin, mais on l'achète trop cher. Je dirai ici une façon d'en avoir meilleur marché que de coutume, qui a été essayée en moi même. S'en servira qui voudra.

Feu mon père, ayant fait toutes les recherches qu'homme peut faire, parmi les gens savants et d'entendement, d'une forme d'institution exquise, fut avisé de cet inconvénient qui était en usage; et lui disait-on que cette longueur que nous mettions à apprendre les langues qui ne leur coûtaient rien ${ }^{1}$ est la seule cause pourquoi nous ne pouvions arriver à la grandeur d'âme et de connaissance des anciens Grecs et Romains. Je ne crois pas que ce en soit la seule cause. Tant y a que l'expédient
Desejaria em primeiro lugar conhecer bem a minha língua e em seguida as dos vizinhos com quem tenho mais relaçóes. O latim e o grego são sem dúvida belos ornamentos mas custam caro demais. Pois direi aqui o modo de adquiri-los mais barato que de costume, modo esse experimentado por mim mesmo. Quem quiser que o adote.

Meu falecido pai, tendo procurado por todos os meios, entre homens de saber e inteligência, a melhor forma de educação, percebia os inconvenientes do método então em uso. Disseram-lhe que o tempo que levávamos a aprender as línguas que a gregos e romanos nada haviam custado, era o único motivo por que não podíamos alcançar a grandeza de alma e os conhecimentos dos antigos. Não creio que essa seja a única causa, mas o que importa no caso é a solução que meu pai encontrou. Logo 
que mon père y trouva, ce fut que, en nourrice et avant le premier dénouement de ma langue, il me donna en charge à un Allemand ${ }^{2}$, qui depuis est mort fameux médecin en France, du tout ignorant de notre langue, et très bien versé en la latine. Cettui-ci, qu'il avait fait venir exprès, et qui était bien chèrement gagé, m’avait continuellement entre les bras. Il en eut aussi avec lui deux autres, moindres en savoir, pour me suivre, et soulager le premier. Ceux-ci ne m'entretenaient d'autre langue que Latine. Quant au reste de sa maison, c'était une règle inviolable que ni lui-même, ni ma mère, ni valet, ni chambrière, ne parlaient en ma compagnie quautant de mots de latin que chacun avait appris pour jargonner avec moi. C'est merveille du fruit que chacun $\mathrm{y}$ fit. Mon père et ma mère $\mathrm{y}$ apprirent assez de latin pour l'entendre, et en acquirent à suffisance pour s'en servir à la nécessité, comme firent aussi les autres domestiques qui étaient plus attachés à mon service. Somme, nous nous latinisâmes tant, qu'il en regorgea jusques à nos villages tout autour, où il $\mathrm{y}$ a encore, et ont pris pied par l'usage, plusieurs appellations latines d'artisans et d'outils. Quant à moi, j'avais plus de six ans avant que j'entendisse non plus de français ou de périgourdin que d'arabesque. Et, sans art, sans livre, sans grammaire ou précepte, sans fouet et sans larmes, j'avais appris du latin, tout aussi pur que mon maitre d'école le savait.

(MONTAIGNE, 1976, p. 172, 174) que desmamei, antes que se me destravasse a língua, confiou-me a um alemão, que morreu médico famoso em França e que ignorava completamente o francês mas possuía perfeitamente o latim. Esse alemão, que meu pai mandara vir de propósito e pagava muito caro, ocupava-se continuamente de mim. Dois outros menos sábios do que ele acompanhavam-me sem cessar quando folgava o primeiro. Os três só me falavam em latim. Quanto aos outros de casa, era regra inviolável que nem meu pai, nem minha mãe, nem criados ou criadas, dissessem em minha presença senão as palavras latinas que haviam aprendido para se entenderem comigo. Excelente foi o resultado. Meu pai e minha mãe adquiriram conhecimento suficiente dessa língua para um caso de necessidade e o mesmo aconteceu com as outras pessoas que lidavam comigo. Em suma, tanto nos latinizamos que a coisa se estendeu às aldeias circunvizinhas onde ainda hoje se conservam, pelo uso, vários nomes latinos de artífices e ferramentas. Quanto a mim, aos seis anos não compreendia mais o francês ou o dialeto da terra do que o árabe. Mas sem método, sem livros, sem gramática, sem regras, sem chicote nem lágrimas, aprendera um latim tão puro quanto o do meu professor. (MONTAIGNE, 1961, p. 236-237)

Tabela 1: Duas versôes do excerto analisado dos Ensaios de Montaigne: a do primeiro estado tipográfico do texto de 1580 e a traduzida para o português em 1961.

1 Frase incorporada por Montaigne posteriormente a 1580. Essa versão da obra é denominada "o exemplar de Bordeaux".

2 Refere-se ao preceptor Horstanus que se tornaria, posteriormente, professor no Colégio de Guyenne. 


\section{Análise imanente do texto}

Neste momento do artigo, apresenta-se uma análise semântico-argumentativa da imanência textual do fragmento exposto na segunda coluna da Tabela 1 no que tange aos idiomas com os quais o filósofo tem contato no capítulo em questão.

No primeiro parágrafo, Montaigne demonstra significativa receptividade em relação a outra(s) língua(s) de suas redondezas, dos vizinhos com quem teve mais contato, apresentando a importância de conhecê-las. Observa-se que não há nenhum indício de culto ao monolinguismo em suas palavras, e sim o contrário, haja vista que ele teria vivido desde criança numa situação, pelo menos, bilíngue, apesar de ter tido contato unicamente com a língua latina. Dessa forma, as línguas dos vizinhos, independentemente de quais ele se refira, ocupam o mesmo grau de importância no seu dia a dia após os seus seis anos de idade, colocando-as em situação de coordenação, e não de subordinação. Quando o filósofo diz "[a língua] dos meus vizinhos [...]", pressupóe-se que os indivíduos com os quais teria tido contato na fase adulta compartilhavam uma única língua comum, sem dar indícios, nesse momento, de outros prováveis idiomas falados em seus arredores.

Montaigne não especifica o que considera efetivamente seu idioma, implicando que se trate do francês, idioma prevalecente nos Ensaios. Quanto às línguas dos vizinhos com quem teria mais contato, Montaigne não deixa explícito se queria conhecer bem tanto a sua língua quanto a língua de seus vizinhos, ou seja, se queria ser equilíngue em ambas ou apenas na sua língua. Pode-se ainda subentender que conhecer bem a sua língua possa se referir tanto à necessidade imediata de comunicação e compreensão orais, pois afirma explicitamente que a língua é um canal fundamental para interagir com os seus semelhantes frequentadores do seu meio e das adjacências; como também possa fazer alusão às quatro habilidades linguageiras da variação erudita do vernáculo latino. Assim, observam-se resquícios filosóficos referentes a políticas linguísticas. Apesar da sua condição de nobre burguês - claramente exposta no excerto quando diz ter criados e criadas à sua disposição quando criança -, Montaigne afirma que é muito onerosa a aprendizagem do latim e do grego, línguas essenciais para a instrução humanística (ARAÚJO, 2013, 5'54”) e para a grandeza da alma. Dessa forma, o prestígio cultural e a erudição 
do indivíduo renascentista estariam diretamente relacionados com o conhecimento linguístico dos vernáculos como língua segunda (ou estrangeira) e que, para o filósofo, o latim teria sido o seu idioma primeiro.

No terceiro parágrafo, no entanto, Montaigne declara que a latinização imperante em seu castelo ultrapassou os muros e acabou chegando aos vilarejos próximos, subentendendo que sua vizinhança seria efetivamente bilíngue em virtude do contato com uma das variantes medievais do latim efetivamente vivo nos domínios dos Montaigne. No mais, de forma indireta, menciona que haveria outras línguas em suas redondezas além do francês, o perigordino e o árabe, legitimando que o bilinguismo se manifestava em ambiente natural. Constata-se que o latim se torna a sua única língua materna até seus seis anos, pressupondo que o filósofo manteria contato em seguida com o francês, com o perigordino e com o árabe. O sistema educacional, citado com severas críticas, é mencionado por Montaigne nesse momento do texto.

O filósofo não fala da complexidade gramatical dos vernáculos muitas vezes difundidas pelo senso comum desde a Antiguidade Clássica, mas sim sobre o processo oneroso de aprendizagem do grego e do latim, línguas historicamente prestigiadas que, aliás, de forma sutil, não são consideradas como estrangeiras em nenhuma das passagens estudadas.

Através da leitura dos dois parágrafos observados, legitimam-se, pelo menos, duas questóes de grande relevância no presente artigo: a atenção do filósofo a respeito do bilinguismo em tempos renascentistas em território francês, porém não exclusivamente francófono; o valor atribuído a determinadas línguas, o motivo pelo qual era dado maior valor a tal idioma e às diversas questões acerca dessas constataçôes.

\section{O bilinguismo e outras questões}

Os parágrafos anteriores apresentam rico objeto de análise sobre o bilinguismo à luz produtiva da literatura do ramo da Linguística Aplicada, mais especificamente das Línguas em Contato. Portanto, esta seção do artigo propóe uma exposição teórica no que concerne ao conceito de bilinguismo e sua prática no século XXI, apontando teorias que legitimem ou que desconstruam o posicionamento (a)típico do Senhor de Montaigne em relação ao seu dia a dia quinhentista. 
$\mathrm{Na}$ contemporaneidade, o bilinguismo é visto como um fenômeno linguístico recorrente que atinge praticamente os quatro cantos do globo terrestre, assim como toda classe social de faixa etária. A manifestação de dois ou mais idiomas tem sido recorrentemente observado, sendo o monolinguismo a exceção. De acordo com Moore (2006, p. 02), há aproximadamente 8 mil línguas faladas em 200 países. No mesmo sentido, Harding e Riley (1986, p. 27) apontam que mais da metade da população mundial é bilíngue, o que comprova a impossibilidade da predominância do monolinguismo. É, portanto, preciso compreender que a relação existente entre as línguas é inerente à condição do bilíngue, desde seu cérebro até sua relação com os outros indivíduos. A diversidade de idiomas começa dentro do próprio sujeito, quando este recorre aos sistemas linguísticos disponíveis como estratégia de comunicação ou por necessidade de se comunicar com o mundo; e também fora do indivíduo, visto que as comunidades linguísticas são sempre heterogêneas. Nesse contexto, oportunizam-se os contatos interidioletal (contato entre indivíduos que compartilham o mesmo idioma) e interlinguístico (contato entre indivíduos que não falam a mesma língua).

É nesse sentido que Montaigne declara, logo em suas primeiras palavras do capítulo aqui analisado, a importância e o gosto pessoal de falar outras línguas: "Desejaria em primeiro lugar conhecer bem a minha língua e em seguida as dos vizinhos com quem tenho mais relaçôes". Assim, é possível constatar que o autor apresenta não somente vontade de compreender outras línguas, mas, sobretudo, demonstra respeito a elas, tendo em vista a importância que ele atribui a essa aprendizagem.

\section{Sobre o conceito de bilinguismo,}

há um continuum que parte dos monolíngues e que chega aos equilíngues. Pertencem, portanto, à categoria dos bilíngues desequilibrados os aprendizes recentes de outra língua (bilíngues incipientes) assim como aqueles que apenas leem em outro sistema ou ainda os que não querem ou não conseguem falar outra língua por razóes pessoais ou de competência, mas a compreendem bem (bilíngues passivos ou receptivos). Também são considerados bilíngues desequilibrados aqueles falantes que atingem alto nível de desempenho em todas as 
habilidades linguísticas de uma língua, mas que ainda assim náo conseguem passar por nativo quando avaliados por um. No extremo do continuum, existem os que são considerados bilíngues equilibrados ou equilíngues, por serem justamente capazes de se desempenhar como nativos de duas ou mais línguas. (MOZZILLO, 2001, p. 4 e 5)

Esse novo sistema linguístico adquirido é denominado interlíngua, de acordo com Selinker (1972, apud MOZZILLO, 2001, p. 68), pois não corresponde nem à língua materna nem à língua alvo do falante, sendo assim um terceiro sistema linguístico. A interlíngua do aprendiz existe a partir do momento em que ele dispóe de rudimentos de, pelo menos, uma das quatro habilidades linguísticas da língua-alvo. $\mathrm{O}$ nível dessa interlíngua pode ser ou não elevado, o que não compromete o seu bilinguismo, pois todo falante de interlíngua de baixo ou alto nível de desempenho é considerado bilíngue desequilibrado.

O conceito de bilinguismo precoce se aplica quando uma criança, de até sete anos de idade, utiliza duas línguas de forma intuitiva e natural em situaçóes motivadas pelas línguas faladas por seus pais, pela língua da babá ou familiares falantes de um idioma diferente do(s) usado(s) pelos pais dessa criança ou ainda pela língua utilizada em ambiente escolar frequentado pela criança. Do nascimento até os três anos, a criança é considerada bilíngue simultânea nas línguas às quais está regularmente exposta e, dos três aos sete, bilíngue consecutiva ${ }^{2}$.

Oportunizando um breve diálogo entre as teorias expostas e a masterpiece de Montaigne, pode-se concluir que o filósofo estava plurilinguisticamente cercado desde a sua infância até a sua fase adulta. A leitura imanente textual dos excertos propostos do Essais não apresenta, aos autores pesquisadores, suporte concreto para afirmar que Montaigne teria sido um bilíngue equilibrado em todas as línguas com as quais tinha contato. Em contrapartida, pode-se propor que se tratava de um bilíngue desequilibrado em alguns pares linguísticos, tendo sido suas demais interlínguas utilizadas frequentemente ao longo de sua vida dentro e fora de seus domínios.

2 Segundo entrevista de Barbara Abdellilah-Bauer à revista "Sciences Humaines" realizada por Nicolas Journet em 2015, disponível em http://www.scienceshumaines.com/grandir-entre-deux-languesentretien-avec-barbara-abdellilah-bauer-et-ranka-bijeljac-babic_fr_34976.html. (JOURNET, 2015). 


\section{Mitos sobre o indivíduo bilíngue}

Neste momento do trabalho, propóe-se a exposição de um apanhado teórico acerca dos mitos e crenças que circundam os sujeitos que interagem com mais de um idioma, aproveitando a ocasião para realizar conexóes com os parágrafos da obra de Montaigne abordados no presente artigo.

As diversas crenças que existem acerca do conceito de bilinguismo influenciam diretamente o indivíduo bilíngue e o seu meio social. Compreender o significado desse conceito e as diversas questóes que com ele estão conectadas pode ser um fator positivo ou negativo, de alta ou baixa relevância na vida de cada sujeito que fala dois ou mais códigos linguísticos. Ainda que o bilinguismo seja um fenômeno que apresente bastantes vantagens no momento das interaçóes, nem sempre os falantes bilíngues ou leigos o compreendem e agem, portanto, de acordo. Assim, equivocadamente, o bilinguismo pode aparentar dispor de aspectos negativos, influenciando negativamente a vida de muitos indivíduos.

Para ilustrar as principais impressóes sobre o indivíduo bilíngue e a influência de tais rótulos na construção dos sujeitos, de acordo com Vieira e Moura (2000, p. 117), existem, pelo menos, dois tipos de poliglotas: o esnobe e o ignorante. Este não considera privilégio o fato de falar duas ou mais línguas, nem entende que seja algo diferente ou negativo; enquanto aquele defende ser extremamente favorável falar duas ou mais línguas, atrelando esse conhecimento linguístico à inteligência. Desta forma, os teóricos propóem dois polos entre as opinióes existentes.

No caso do poliglota esnobe, existem algumas questóes que merecem ser apresentadas. Primeiramente, um falante bilíngue poder-se-ia considerar superior socioeconomicamente a um falante monolíngue, haja vista que o estudo de línguas seria restrito àqueles que dispunham (e que dispóem) de elevados recursos financeiros não somente na época de Montaigne, mas também na contemporaneidade. O filósofo, filho de uma família recém-enobrecida no início do século XVI, teve uma formação humanística bastante sólida (ARAÚJO, 2013, 5'54”). Os seus preceptores, muito bem pagos que custavam caro, só lhe falavam em latim, que, logo, se tornou a língua materna de Montaigne. Esse idioma exprimia expoente sabedoria, inclusive moral, e deixava transparecer toda a excelência humana fortemente explorada pelos humanistas, sendo o latim um instrumento fundamental para se ter acesso aos grandes pensadores da Antiguidade. 
O cenário pós-renascentista de valorização do bilinguismo tende a permanecer muito similar ao dos dias de hoje, pois propaga-se que aprender outros idiomas seja um privilégio, ainda que, conforme Vieira e Moura (2000, p. 114), o acesso a línguas estrangeiras seja um direito de todo cidadáo segundo a Declaração Universal dos Direitos do Homem proclamada pela ONU (Organização das Nações Unidas) e segundo a Declaração Universal dos Direitos Linguísticos.

Ainda sobre o poliglota esnobe, existe a crença de que o falante de línguas estrangeiras é mais inteligente que o monolíngue. Tal questão até pode ser argumentada e legitimada, mas para isso é preciso esclarecer outras questôes. Em ambiente natural, todo sujeito é capaz de aprender outra língua sem grandes esforços, não entrando em questóes de desempenho linguístico e partindo do princípio de que o tempo de exposição seja suficiente e o filtro afetivo seja baixo - o que facilita, de acordo com Krashen (1982, p. 30), a aquisição de outro idioma.

O bilíngue que aprende uma língua estrangeira em sala de aula, em situação artificial, portanto, é que poderia ser considerado mais inteligente, já que todo seu desempenho depende, em grande parte, do esforço individual aplicado e de sua aptidão linguística. Com isso, nota-se que existem duas possibilidades de aprender um idioma e apenas uma delas exige algum tipo de habilidade. Isso não significa, porém, que um indivíduo bilíngue tenha mais capacidade intelectual e prática de aprender e desempenhar todas e quaisquer tarefas cotidianas possíveis. $\mathrm{O}$ falante bilíngue pode ter grande facilidade em aprender outras línguas, assim como ler e escrever com maior competência, mas isso não significa necessariamente que ele seja tão bom quanto nas demais do dia a dia.

O bilíngue ignorante, no entanto, representa aquele indivíduo que pode não considerar positivo falar duas ou mais línguas - principalmente se essas línguas forem de pouco prestígio. Além disso, ele pode não se considerar bilíngue justamente por não saber o significado do conceito. Assim como o esnobe, é possível notar que o conceito de bilinguismo, bem como todas as diversas questóes que o cercam, está permeado de crenças e mitos, tanto daqueles que enaltecem o indivíduo, quanto daqueles que o subestimam.

Apesar da existência de tais estereótipos em torno do falante bilíngue, foi possível notar no texto de Montaigne que o autor náo deixa transparecer preconceito nem interlinguístico nem intralinguístico de nenhuma espécie. Em 
momento algum, a palavra dialeto é utilizada no excerto de análise, podendo evidenciar algum indício de desprezo de outra língua em seu texto. Quando cita o perigordino, o filósofo opta por chamá-lo assim em vez de pô-lo em condição desprestigiada em relação ao francês, pois poderia ter se referido à língua da região como um dialeto do francês. Assim, fortalece-se o princípio de um respeito com as manifestaçôes linguísticas sem indícios de preconceito, independentemente de quais idiomas sejam.

\section{Conclusão}

O bilinguismo não fazia parte apenas da vida do Senhor de Montaigne, mas faz, efetivamente, da maioria dos indivíduos do século XXI, legitimando que o monolinguismo é minoritariamente manifestado no planeta Terra.

O pai da Teoria da Complexidade, o francês Edgar Morin, em entrevista à revista on-line Terraeco, cita uma frase de Montaigne: "Eu vejo, em todo homem, meu compatriota ${ }^{3}$," legitimando a postura cidadão do mundo de um indivíduo herdeiro de uma tradição medievo-renascentista, porém imerso no barroco francês durante a produção dos Ensaios. Ainda Morin (MORIN, 2015, 15'17'), ao lado do islamólogo Tariq Ramadan, ambos entrevistados pelos jornalistas Eric Naulleau e Eric Zemmour, põe a França numa condição tão multiétnica quanto o Brasil, assim como a maioria dos países do globo apresenta conjuntura multicultural. "A França é uma e multicultural. A composição do Marrocos, por exemplo, é um país multicultural porque há berberes, franceses e outros. Vejam a cultura do sul do Brasil". 4

O "Complexo da Torre de Babel" permanecia, permanece e ainda tende a permanecer no inconsciente coletivo do ser humano, defendendo, assim, tanto o monolinguismo quanto a homogeneização linguística. Não se observa, nas palavras de Montaigne, tal trauma de Babel, muito pelo contrário: ele reconhece a existência de outros idiomas e ressalta a importância de interagir com eles para viabilizar relaçóes com sua vizinhança. O Senhor de Montaigne,

3 Texto original : 'Je vois en tout homme mon compatriote” (MORIN, 2015, 15'17").

4 Texto original : "La France est une et multiculturelle. La constitution du Maroc, par exemple, c'est un pays multiculturel parce qu'il y a des Berbères, des Français et des autres. Regardez la culture dans le sud du Brésil” (MORIN, 2015, 15’17”). 
há pouco mais de 400 anos e há quase quatro séculos antes do nascimento de Saussure, já discutia sobre a necessidade de promover o bilinguismo, principalmente num mundo conectado graças aos adventos tecnológicos: em sua época, a navegação e os passos iniciais nos processos de industrialização; em pleno século XXI, as comunicaçóes e os transportes. Estes últimos têm deixado o mundo cada vez menor, fomentando, consequentemente, o intercâmbio multicultural e plurilinguístico e fazendo emergir, cada vez mais, novos cidadãos do mundo.

\section{Referências}

ARAÚJO, S. X. G. Os Ensaios de Montaigne com Sérgio Xavier Gomes de Araújo. In: Literatura Fundamental 23. Univesp TV. Disponível em https:// www.youtube.com/watch?v=RBfc-J5_2Tw. Acesso em 2/5/2016.

HARDING, E.; RILEY, P. The Bilingual Family: a Handbook for Parents. USA: Cambridge University Press, 1986.

JOURNET, N. Grandir entre deux langues - Entretien avec Barbara Abdellilah-Bauer et Ranka Bijeljac-Babic, 2015. Revista Sciences Humaines. Disponível em http://www.scienceshumaines.com/grandir-entre-deux-languesentretien-avec-barbara-abdellilah-bauer-et-ranka-bijeljac-babic_fr_34976.html. Acesso em 16/5/2016.

KRASHEN, S. Principles and Practice in Second Language Acquisition. University of Southern California, 1982.

MONTAIGNE, M. E. Ensaios Livro I. Tradução de Sérgio Milliet. Porto Alegre: Editora Globo, 1961.

. Les Essais: Textes choisis. 12e édition. Collection Nouveaux Classiques illustrés. Dirigée par Hubert Carrier. Evreux: Hachette, 1976.

. Essais de Michel de Montaigne: texte original de 1580 avec les variantes des

éditions de 1582 et 1587 . Publié par R. Dezeimeris \& H. Barckhausen. Bordeaux: Féret et Fils, 1870. Tome 1. Disponível em http://gallica.bnf.fr/ ark:/12148/bpt6k102435w/f3.image.langFR. Acesso em 16/5/2016.

MOORE, D. Plurilinguismes et école. Collection LAL. Paris: Editions Didier, 2006.

MORIN, E. Il n'y a pas de solution, mais il y a une voie. Terra Eco, p. 01-09. Disponível em http://www.terraeco.net/Edgar-Morin-Il-n-y-a-pas-de,56141. html. Acesso em 16/5/2016. 
. Ramadan/Morin: le duo de l'impossible? Zemmour et Naulleau. Disponível em https://www.youtube.com/watch?v=GtaNI00W0Gk. Acesso em $16 / 5 / 2016$.

MOZZILLO, I. A conversação bilíngue dentro e fora da sala de aula de língua estrangeira. In: HAMMES, W.; VETROMILLE-CASTRO, R. (orgs.) Transformando a sala de aula, transformando o mundo: ensino e pesquisa em língua estrangeira. Pelotas: Educat, 2001.

SELINKER, L.. Interlanguage. IRAL, International Review of Applied Linguistics in Language Teaching, 1972.

VIEIRA, J.; MOURA, H. Língua estrangeira: direito ou privilégio? In: LOPES DA SILVA, F.; MOURA, H. O direito à fala. A questão do preconceito lingüístico. Florianópolis: Editora Insular, 2000.

\title{
The Montaigne's Essays bilingual subject
}

\begin{abstract}
The Lord of Montaigne is positioned positively to the practice of bilingualism in his post-Renaissance's Essays. Based on the contemporary literature of Languages in Contact, this paper proposes a dialogue between an excerpt of this masterpiece and myths and beliefs related to the individual bilingual. Thus, it is suggested that the plurilinguism predominates instead of monolingualism since the Fifteenth Century.
\end{abstract}

KEYWORDS: Bilingualism; Montaigne; The Essays.

Recebido em: 16/05/2016 Aprovado em: 09/11/2016 